
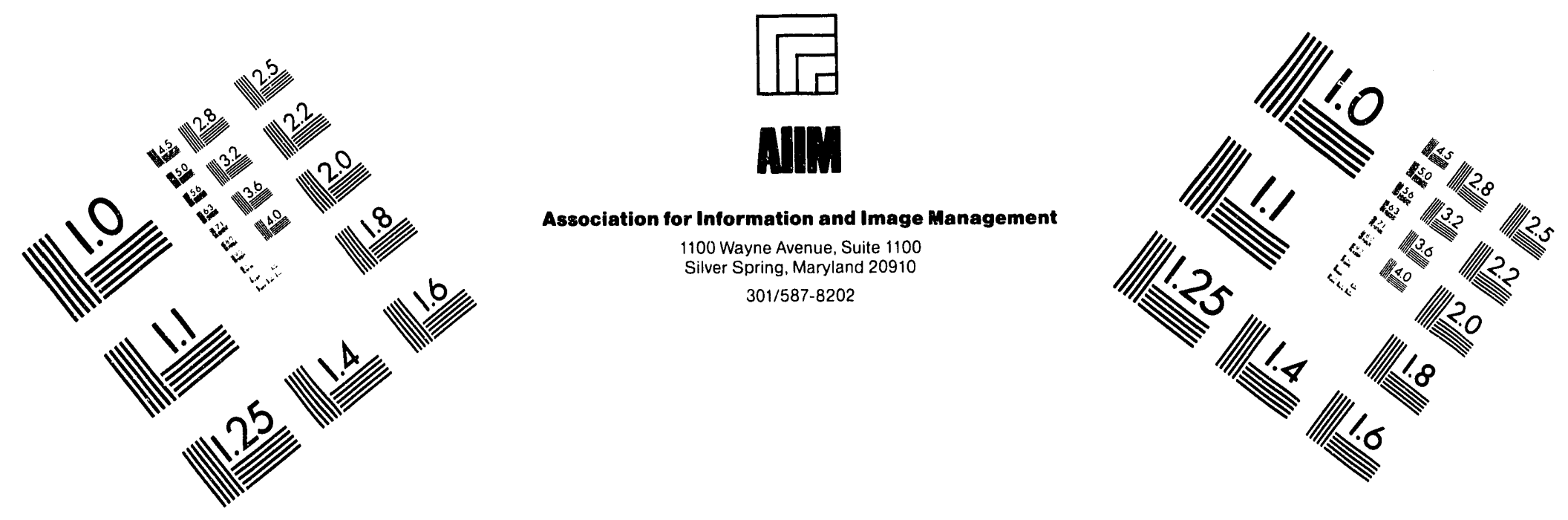

\title{
Centimeter
}

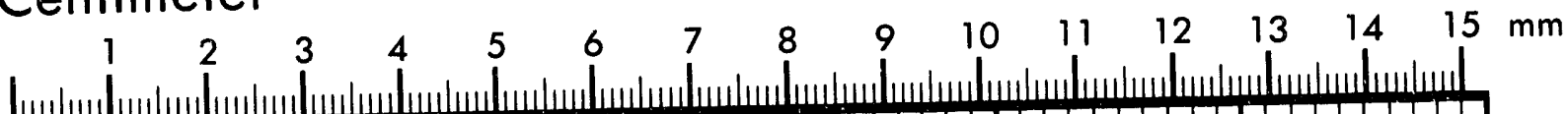
$\mid$ Inches
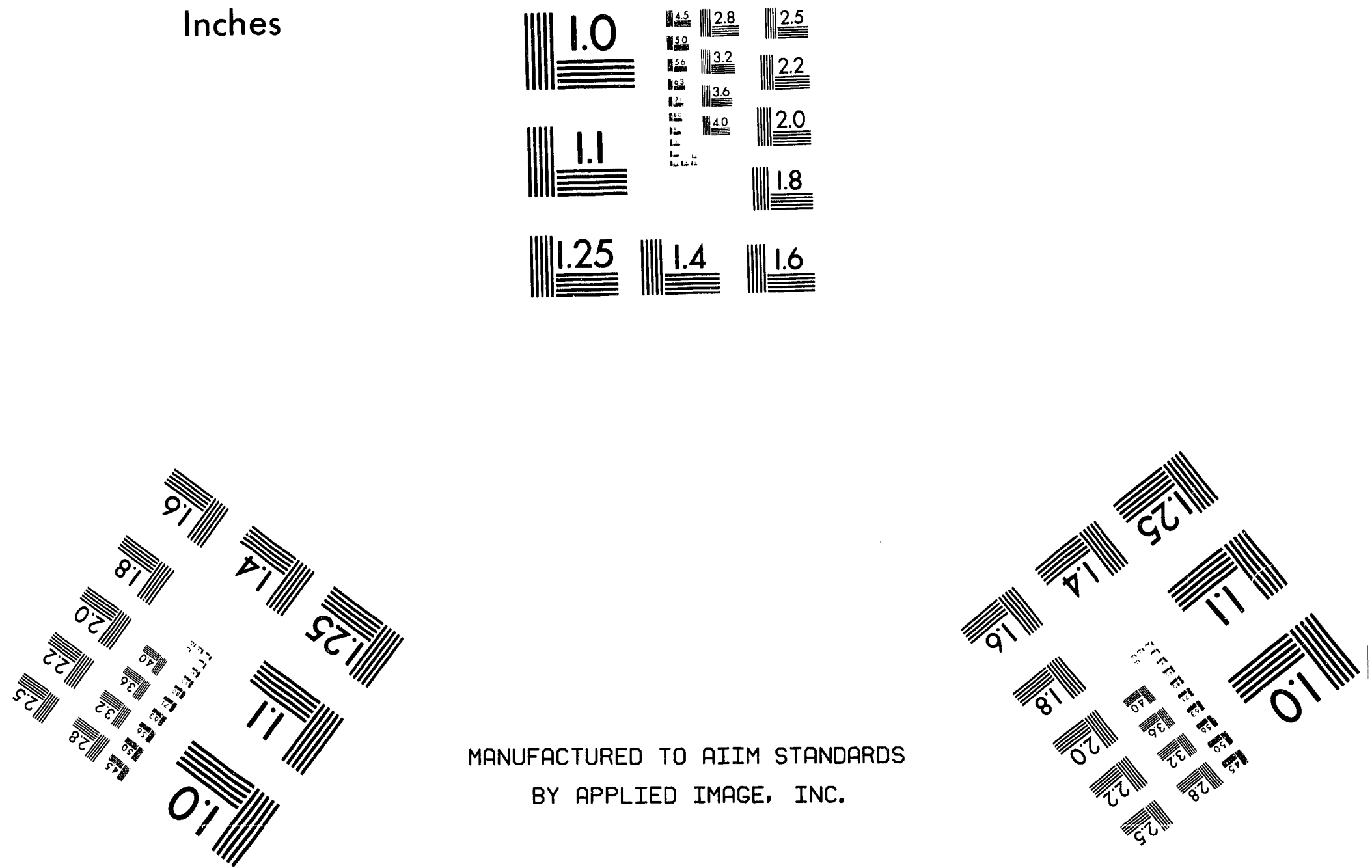

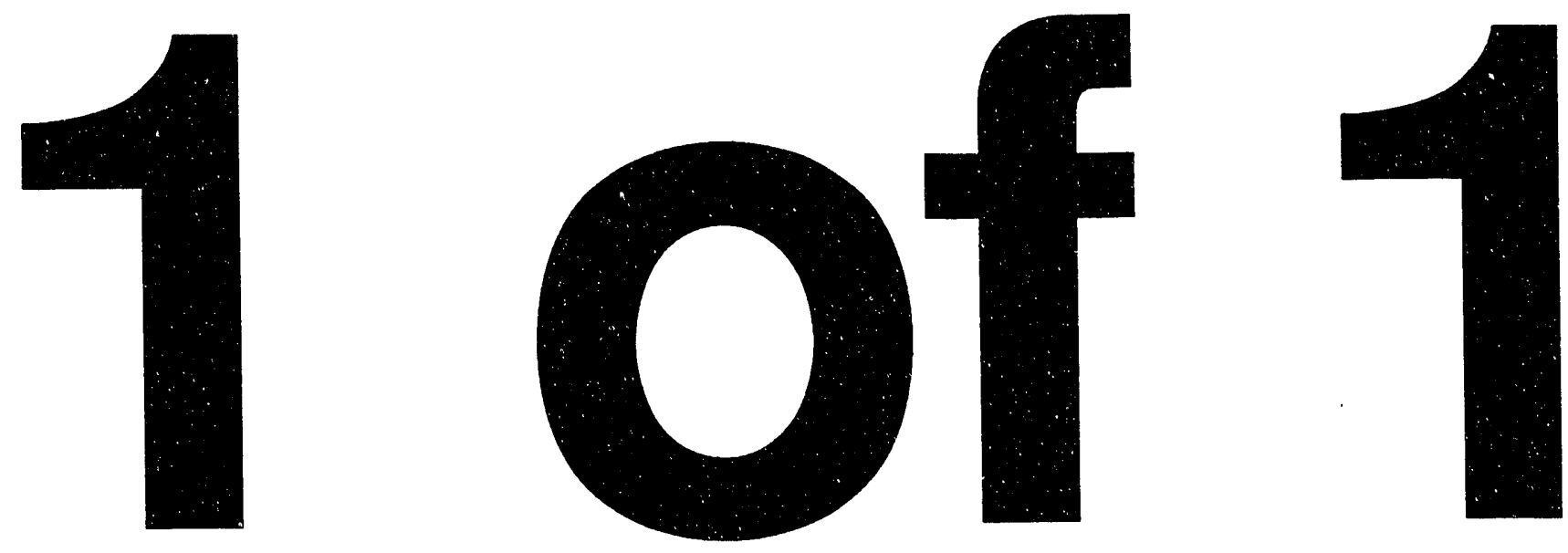


$$
\text { DOE/ER/Ci.1056- Ti }
$$

\title{
The Department of Energy's Atmospheric Chemistry Program
}

\author{
A Critical Review
}

Committee on Atmospheric Chemistry

Board on Atmospheric Sciences and Climate Commission on Geosciences, Environment, and Resources

National Research Council

NATIONAL ACADEMY PRESS

Washington, D.C. 1991

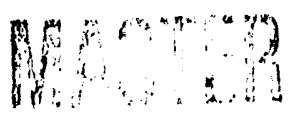


NOTICE: The project that is the subject of this report was approved by the Governing Board of the National Research Council, whose members are drawn from the councils of the National Academy of Sciences, the National Academy of Engineering, and the Institute of Medicine. The members of the committee responsible for the repor were chosen for their special competences and with regard for appropriate balance.

This report has been reviewed by a group other than the authors according to procedures approved by a Report Review Committee consisting of members of the National Academy of Sciences, the National Academy of Engineering, and the Institute of Medicine.

The National Academy of Sciences is a private, nonprofit, self-perpetuating society of distinguished scholars engaged in scientific and engineering research, dedicated to the furherance of science and technology and to their use for the general welfare. Upon the authority of the charter granted to it by the Congress in 1863, the Academy has a mandate that requires it to advise the federal government on scientific and technical matters. Dr. Frank Press is president of the National Academy of Sciences.

The National Academy of Engineering was established in 1964, under the charter of the National Academy of Sciences, as a parallel organization of outstanding engineers. It is autonomous in its administration and in the selection of its members, sharing with the National Academy of Sciences the responsibility for advising the federal govermment. The National Academy of Engineering also sponsors engineering programs aimed at meeting national needs, encourages education and research, and recognizes the superior achievements of engineers. Dr. Rober M. White is president of the National Academy of Engineering.

The Institute of Medicine was established in 1970 by the National Academy of Sciences to secure the services of eminent members of appropriate professions in the examination of policy matters pertaining to the health of the public. The Institute acts under the responsibility given to the National Academy of Sciences by its congressional charter to be an adviser to the federal government and, upon its own initiative, to identify issues of medical care, research, and education. Dr. Samuel $O$. Thier is president of the Institute of Medicine.

The National Research Council was organized by the National Academy of Sciences in 1916 to associati the broad community of science and technology with the Academy's purposes of furthering knowledge and advising the federal govemment. Functioning in accordance with general policies determined by the Academy, the Council has become the principal operating agency of both the National Academy of Sciences and the National Academy of Engineering in providing services to the government, the public, and the scientific and engineering communities. The Council is administered jointly by both Academies and the Institute of Medicine. Dr. Frank Press and Dr. Rober M. White are chairman and vice chairman, respectively, of the National Research Council.

Support for this project was provided by the Department of Energy under Grant Number DE-FG05-90ER61056.

A limited number of copies of this report are available from

Board on Atmospheric Sciences and Climate (HA 594)

National Research Council

2101 Constitution Avenue, N.W.

Washington, DC 20418

Printed in the United States of America 


\section{COMMITTEE ON ATMOSPHERIC CHEMISTRY}

CHARLES E. KOLB (Chair), Aerodyne Research, Inc., Billerica, Massachusetts

ROBERT J. CHARLSON, University of Washington, Seattle, Washington

FRED C. FEHSENFELD, Environmental Research Laboratories, National

Oceanic and Atmospheric Administration, Boulder, Colorado

BARBARA FINLAYSON-PITTS, California State University, Fullerton, California

HAROLD S. JOHNSTON, University of California, Berkeley, California STUART A. PENKETT, University of East Anglia, Norwich, England JOSEPH M. PROSPERO, University of Miami, Miami, Florida

\section{DISCLAIMER}

This report was prepared as an account of work sponsored by an agency of the United States Government. Neither the United States Government nor any agency thereof, nor any of their employees, makes any warranty, express or implied, or assumes any legal liability or responsibility for the accuracy, completeness, or usefulness of any information, apparatus, product, or process disclosed, or represents that its use would not infringe privately owned rights. Reference herein to any specific commercial product, process, or service by trade name, trademark, manufacturer, or otherwise does not necessarily constitute or imply its endorsement, recommendation, or favoring by the United States Government or any agency thereof. The views and opinions of authors expressed herein do not necessarily state or reflect those of the United States Government or any agency thereof. 


\section{BOARD ON ATMOSPHERIC SCIENCES AND CLIMATE}

JOHN A. DUTTON (Chair), Pennsylvania State University, University Park,

Pennsylvania

JON F. BARTHOLIC, Michigan State University, East Lansing, Michigan

E. ANN BERMAN, Tri-Space, Inc., McLean, Virginia

RAFAEL L. BRAS, Massachusetts Institute of Technology, Cambridge,

Massachusetts

MOUSTAFA T. CHAHINE, California Institute of Technology, Pasadena,

California

ROBERT A. DUCE, University of Rhode Island, Kingston, Rhode Island

THOMAS E. GRAEDEL, AT\&T Bell Laboratories, Murray Hill, New Jersey

DAVID D. HOUGHTON, University of Wisconsin, Madison, Wisconsin

RICHARD G. JOHNSON, Network Systems, Stanford, California

EUGENIA KALNAY, National Meteorological Center, National Oceanic and Atmospheric Administration, Washington, D.C.

RICHARD S. LINDZEN, Massachusetts Institute of Technology, Cambridge, Massachusetts

SYUKURO MANABE, Geophysical Fluid Dynamics Laboratory, National

Oceanic and Atmospheric Administration, Princeton, New Jersey

GERALD R. NORTH, Texas A\&M University, College Station, Texas

JAMES J. O'BRIEN, Florida State University, Tallahassee, Florida

JOANNE SIMPSON, Goddard Space Flight Center, National Aeronautics

and Space Administration, Greenbelt, Maryland

\section{Ex-Officio Members}

ERIC J. BARRON, Pennsylvania State University, University Park,

Pennsylvania

PETER V. HOBBS, University of Washington, Seattle, Washington

CHARLES E. KOLB, Aerodyne Research, Inc., Billerica, Massachusetts

DONALD J. WILLIAMS, The Johns Hopkins University, Baltimore,

Maryland

\section{Staff}

JOHN S. PERRY, Staff Director

WILLIAM A. SPRIGG, Associate Staff Director 


\section{COMMISSION ON GEOSCIENCES, ENVIRONMENT, AND RESOURCES}

M. GORDON WOLMAN (Chair), The Johns Hopkins University, Baltimore, Maryland

ROBERT C. BEARDSLEY, Woods Hole Oceanographic Institution, Woods Hole, Massachusetts

B. CLARK BURCHFIEL, Massachusetts Institute of Technology, Cambridge, Massachusetts

RALPH J. CICERONE, University of California, Irvine, California

PETER S. EAGLESON, Massachusetts Institute of Technology, Cambridge, Massachusetts

HELEN M. INGRAM, University of Arizona, Tucson, Arizona

GENE E. LIKENS, New York Botanical Gardens, New York, New York

SYUKURO MANABE, Geophysical Fluid Dynamics Laboratory, National

Oceanic and Atmospheric Administration, Princeton, New Jersey

JACK E. OLIVER, Cornell University, Ithaca, New York

PHILIP A. PALMER, E.I. du Pont de Nemours \& Co., Newark, Delaware

FRANK L. PARKER, Vanderbilt University, Nashville, Tennessee

DUNCAN T. PATTEN, Arizona State University, Tempe, Arizona

MAXINE L. SAVITZ, Allied Signal Aerospace Company, Torrance, California

LARRY L. SMARR, University of Illinois, Urbana-Champaign, Illinois STEVEN M. STANLEY, Case Western Reserve University, Cleveland, Ohio

CRISPIN TICKELL, Radcliffe Observatory, Oxford, England

KARL K. TUREKIAN, Yale University, New Haven, Connecticut

IRVIN L. WHITE, New York State Energy Research and Development Authority, Albany, New York

JAMES H. ZUMBERGE, University of Southern California, Los Angeles, California

\section{Staff}

STEPHEN RATTIEN, Executive Director

STEPHEN D. PARKER, Associate Executive Director

JANICE MEHLER, Assistant Executive Director

JEANETTE SPOON, Administrative Associate

CARLITA PERRY, Administrative Assistant 


\section{Preface}

In response to a request from the Department of Energy's (DOE) Office of Health and Environmental Research (OHER), the Committee on Atmospheric Chemistry has reviewed OHER's Atmospheric Chemistry Program (ACP). This report contains the committee's evaluation and critique arising from that review.

The review process included a two-day symposium held at the National Academy of Sciences on September 25 and 26, 1990, that focused on presenting the ACP's current components, recent scientific accomplishments, and scientific plans. The symposium consisted of more than 30 presentations by ACP management, scientific staff from DOE's national laboratories, and selected university contractors. Discussion between and among committee members and ACP personnel was intensive. Following the symposium, committee members met in a one-day executive session to formulate and outline this report.

In undertaking this review, OHER and ACP management requested that the committee attempt to answer several specific questions involving the program's technical capability and productivity, its leadership and organization, and its future direction. These questions are given in the Appendix.

This report represents the committee's response to the questions posed in the Appendix. Chapter 1 explores the committee's view of the role that atmospheric chemistry could and should assume within the DOE and its prospective National Energy Strategy. Chapter 2 assesses the current ACP, Chapter 3 presents recommendations for revising and strengthening it, and Chapter 4 restates the committee's conclusions and recommendations.

The cooperation of many scientists and managers within DOE was essen- 


\section{viii}

tial and unfailingly proffered during this review. The committee greatly appreciated this and the skillful assistance of National Research Council staff members John Perry and William Sprigg, and consultant Fred White.

Charles E. Kolb, Chair

Committee on Atmospheric Chemistry 


\section{Contents}

1 WHY IS ATMOSPHERIC CHEMISTRY IMPORTANT TO DOE?

Atmospheric Chemistry and the National Energy Strategy, 1

Atmospheric Chemistry and Energy Production and Use, 2

2 ASSESSMENT OF THE CURRENT DOE ATMOSPHERIC CHEMISTRY CAPABILITIES

Overview of the Current DOE Atmospheric Chemistry

Program Activities, 5

Review of Current Programs, 8

3 RECOMMENDATIONS FOR REVISING AND STRENGTHENING THE DOE ATMOSPHERIC CHEMISTRY PROGRAM

Focus on Future Efforts, 16

Recommendations for National Laboratory Programs, 18

Intraprogram Interactions, 22

Interactions with Other Federal and International Programs, 23

4 CONCLUSIONS AND RECOMMENDATIONS

Conclusions, 25

Recommendations, 26

REFERENCES

ACRONYMS

CHEMICAL SYMBOLS AND ABBREVIATIONS

APPENDIX

Questions Posed for the Atmospheric Chemistry Program

Review, 33 


\section{1 \\ Why Is Atmospheric Chemistry Important to DOE?}

\section{ATMOSPHERIC CHEMISTRY AND THE NATIONAL ENERGY STRATEGY}

In July 1989 the president directed the secretary of energy to initiate development of a comprehensive National Energy Strategy (NES). Although the NES is not yet final, the Department of Energy (DOE) published an interim report in April 1990. That document identified four themes as cornerstones for the evolving NES and summarized comments from a series of public meetings. The themes are (1) to increase efficiency of energy use, (2) to secure future energy supplies, (3) to respect the environment, and (4) to fortify foundations.

The third theme-respecting the environment-was amplified by reproducing public comment on a series of environmental issues with significant air quality components. Local and regional issues include photochemical air pollution driven by significant sources of volatile organic compounds (VOCs) from automobiles and nitrogen oxides $\left(\mathrm{NO}_{x}\right)$ produced by fossil fuel combustion in both automobile engines and stationary industrial and power generation combustors; acid deposition driven by sulfur dioxide $\left(\mathrm{SO}_{2}\right)$ emissions from stationary power plants and $\mathrm{NO}_{x}$ from automotive sources as well as stationary combustors; air toxic emissions, including VOCs, carbon monoxide ( $\mathrm{CO}$ ), heavy metals from oil- and coal-fired boilers, refineries, oil and gas production fields, and transportation sources; and indoor air quality degradation due to emissions from stoves, space heaters, and building materials exacerbated by low air exchange rates in tight, energy-efficient buildings. 
Global environmental issues include atmospheric warming driven by greenhouse trace gas buildup, including carbon dioxide $\left(\mathrm{CO}_{2}\right)$, nitrous oxide $\left(\mathrm{N}_{2} \mathrm{O}\right)$, and methane $\left(\mathrm{CH}_{4}\right)$ emissions from fuel production and combustion systems and chlorofluorocarbon (CFC) emissions from refrigeration and air conditioning units, and depletion of stratospheric ozone triggered by CFCs and $\mathrm{N}_{2} \mathrm{O}$ photochemistry (U.S. DOE, 1990). The DOE's Office of Health and Environmental Research's (OHER) Atmospheric Chemistry Program (ACP) now concentrates on tropospheric chemistry and does not deal with the stratosphere; consequently, this report is similarly constrained. Yet in view of the importance of stratospheric ozone depletion and the interplay between global tropospheric and stratospheric processes, the ACP may need to consider expanding its sphere of interest beyond the troposphere.

The atmospheric chemistry issues identified in the NES interim report (U.S. DOE, 1990) are impressive and challenging. Their intrinsic length scales ranged from less than 10 meters for air quality inside an individual building to tens of thousands of kilometers for global warming. They involve time scales from seconds for deposition of large airborne toxic particles near a source to hundreds of years for some key greenhouse gas atmospheric lifetimes.

Because the DOE is mission oriented, it seems clear that the ACP must respond to issues raised by the NES as it evolves and is implemented. Most major programs envisioned by the NES, including fossil fuel production and use, renewable energy source development and use, nuclear energy use and nuclear fuel processing, energy conservation and energy-related waste disposal and remediation are certain to involve atmospheric chemistry issues such as those listed above. It is apparent to the committee that a strong and coherent atmospheric chemistry research, monitoring, and assessment capability with broad-based laboratory and field measurement facilities, coupled with comprehensive data analyses and atmospheric modeling and assessment skills, will be required to develop, assess, and successfully implement the NES.

\section{ATMOSPHERIC CHEMISTRY AND ENERGY PRODUCTION AND USE}

Production and use of energy resources contribute to a variety of environmental problems currently addressed by the atmospheric chemistry community. These problem areas and the role that energy production and use play, or may play, are briefly indicated below. The topics are ordered by spatial scale, from local to global-not by perceived priority.

\section{Indoor Air Quality}

Ventilation rates inside homes and commercial and public buildings of- 
ten are restricted to conserve energy used for heating and air conditioning. Reduced ventilation rates can lead to unhealthy buildup of combustion gases $\left(\mathrm{NO}_{x}, \mathrm{CO}\right.$, etc.) and emissions from construction and furnishing materials (VOCs) (NAS, 1981; Samet et al., 1987). Fuel-switching strategies that enhance natural or compressed gas use for cooking, drying clothes, and other internal purposes can greatly increase indoor $\mathrm{NO}_{x}$ levels (Samet et al., 1987; Ryan et al., 1988). Factors controlling the emission, chemical evolution, and removal of most important indoor air pollutants are poorly understood.

\section{Air Toxic Emission, Evolution, and Deposition}

Coal- and oil-fired power plants can emit copious amounts of $\mathrm{SO}_{2}, \mathrm{NO}_{x}$, particulate and airborne metals, and VOCs (Graedel, 1978). High levels of $\mathrm{CO}, \mathrm{NO}_{x}$, and VOCs can arise from automotive sources (OTA, 1989). Natural gas and petroleum production can emit ammonia, hydrogen sulfide $\left(\mathrm{H}_{2} \mathrm{~S}\right)$, $\mathrm{CO}$, and VOCs, and geothermal systems produce $\mathrm{H}_{2} \mathrm{~S}$ (Graedel, 1978). Each of these sources may adversely affect local structures, vegetation, animals, and people. Assessment of their impacts requires knowledge of emission rates, gas and heterogeneous (e.g., cloud, fog, and aerosol) reaction rates, and deposition processes.

\section{Urban and Regional Photochemical Air Pollution}

The National Research Council is preparing an extensive report on tropospheric ozone production due to photochemical air pollution on the local, regional, and even continental scales. The pivotal role of VOCs and $\mathrm{NO}_{x}$ emissions from transportation, power generation, and industrial energy sources is clear. A recent Office of Technology Assessment document (OTA, 1989) also detailed these issues.

There are strong indications that photochemical activity is producing a significantly growing level of tropospheric ozone over Europe and North America. This situation is manifested even at sites remote from major pollution sources, and it may have significant impacts on the greenhouse problem as a result of ozone's direct infrared activity as well as the implied impacts on the oxidation rate of hydrogen-containing greenhouse species such as $\mathrm{CH}_{4}$.

The 1990 amendments to the Clean Air Act will have significant impacts on energy production and transportation segments of the U.S. economy. Future Clean Air Act amendments or Environmental Protection Agency regulations can be expected to have further implications. DOE programs in fossil energy use, energy conservation, alternate fuels development, and renewable energy sources may all require $\mathrm{ACP}$ guidance to address this problem adequately. 


\section{Acid Deposition}

The National Acid Precipitation Assessment Program (NAPAP) has implicated $\mathrm{NO}_{x}$ and $\mathrm{SO}_{2}$ emissions from transportation, power generation, and industrial energy systems in the acid deposition problem. Elements of the current ACP have made major contributions to understanding the processes that connect $\mathrm{NO}_{x}$ and $\mathrm{SO}_{2}$ emissions to the rate and distribution of nitrate $\left(\mathrm{NO}_{3}\right)$ and sulfate $\left(\mathrm{SO}_{4}\right)$ deposition. However, as the NAPAP enters a new phase, the need continues for further re.jearch on these processes to determine how proposed modifications of fossil energy combustion systems may affect acid deposition.

\section{Effect of Atmospheric Aerosols on Visibility and Radiation Transport}

The chemistry of the formation and growth of atmospheric aerosols and their role in visibility degradation on local and regional scales, their direct effects on the global atmospheric albedo, and their indirect effects on albedo through cloud nucleation are all topics of growing concern. Current hot topics include the role of power-plant-generated $\mathrm{SO}_{4}$ aerosol on haze in the Grand Canyon (NAS, 1990), the global effects of $\mathrm{SO}_{4}$ aerosol scattering (Charlson et al., 1990), and dimethyl-sulfide-driven production of marine cloud condensation nuclei (Charlson et al., 1987; Schwartz, 1988).

With power plants and smelters the major sources of $\mathrm{SO}_{4}$ aerosol, the DOE has an obvious interest in these evolving issues.

\section{Greenhouse Gas Growth and Control}

Several major greenhouse gas sources have direct links to energy systems. These include $\mathrm{CO}_{2}$ emissions from fossil fuel combustion (Rotty and Masters, 1985), $\mathrm{CH}_{4}$ emissions from natural gas and coal production and use (U.S. EPA, 1990), $\mathrm{N}_{2} \mathrm{O}$ from fluidized bed coal combustors (Kramlich et al., 1989), and CFCs from air conditioning and refrigeration systems (WMO, 1989). Photochemically produced tropospheric ozone $\left(\mathrm{O}_{3}\right)$ is also a serious greenhouse issue.

As the NES is defined and implemented, the relative importance of the topics discussed above should become more apparent. The following chapters review current ACP capabilities to address these energy-related atmospheric chemistry issues and recommend actions to strengthen DOE's capability to respond to challenges presented by the NES. 


\section{2}

\section{Assessment of the Current DOE Atmospheric Chemistry Capabilities}

\section{OVER VIEW OF THE CURRENT DOE ATMOSPHERIC CHEMISTRY PROGRAM ACTIVITIES}

Management of the Office of Health and Environmental Research (OHER) and its Atmospheric and Climate Research Division (ACRD) has recently consolidated most of the Department of Energy's (DOE) tropospheric research activities into an organized Atmospheric Chemistry Program (ACP). (Figure 2.1 shows an organization chart; Table 2.1 lists current $\mathrm{ACP}$ objectives.)

Program management is sound and beneficially aggressive in forging scientifically based plans. A capable scientific director is in place.

The major components of the program are within the DOE's national laboratory structure; some activities, notably, components of the Multi-State Atmospheric Power Production Pollution Study (MAP3S) precipitation monitoring network, are contracted to academic laboratories. Most ACP activities were designed to meet the needs of the National Acid Precipitation Assessment Program (NAPAP), which recently completed its first phase of research. The committee notes that although some DOE activities dealing with topics of current or possible future interest to the $A C P$ are not yet part of the program, they should be considered for inclusion. These include the indoor air quality program at Lawrence Berkeley Laboratory (LBL), the tropospheric modeling activities at Lawrence Livermore National Laboratory (LLNL), some laboratory studies at Los Alamos National Laboratory, and certain atmospheric aerosol and cloud condensation nuclei (CCN) projects in the ACRD's new Atmospheric Radiation Measurement (ARM) 


\section{6}

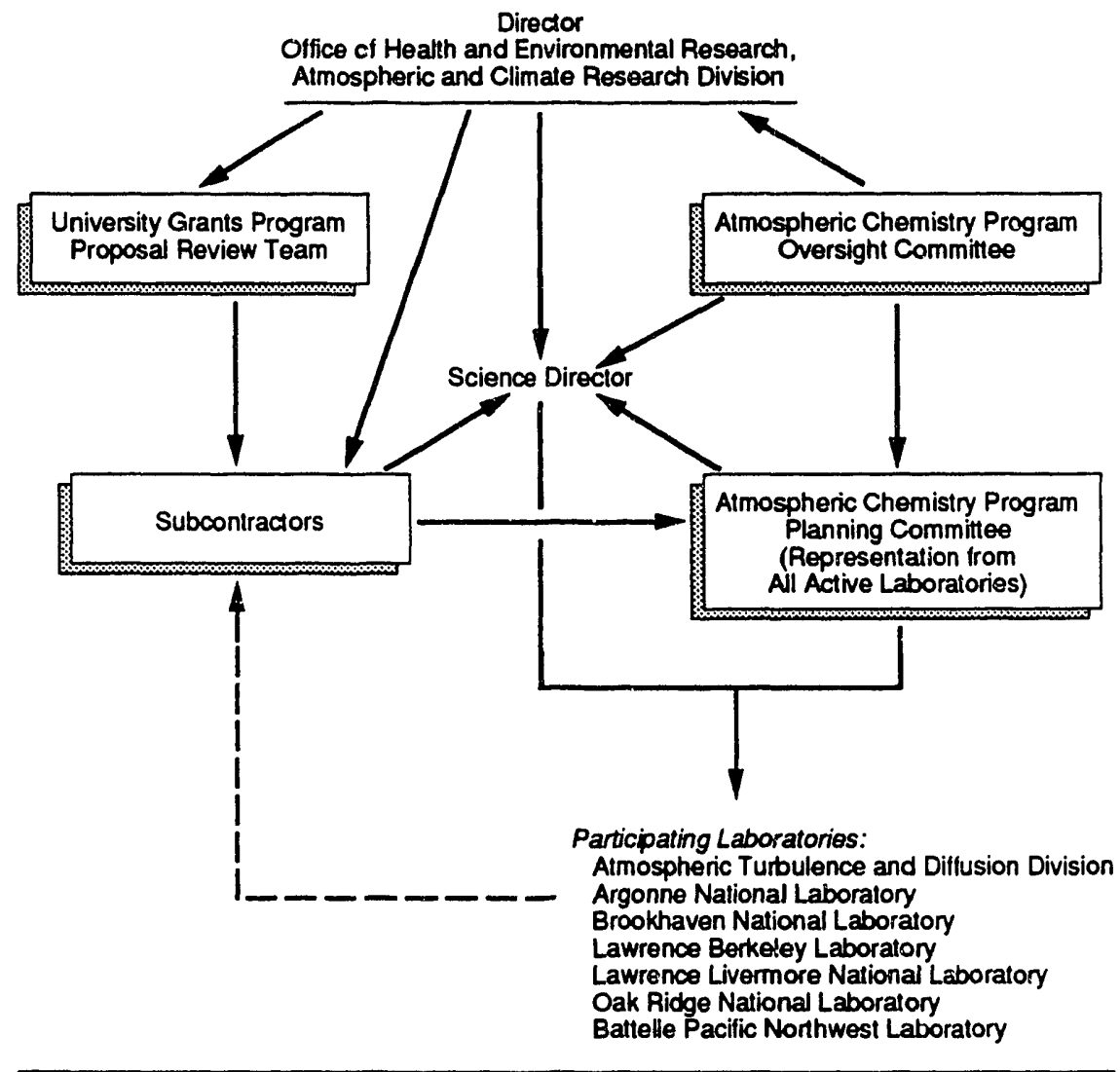

FIGURE 2.1 ACP organization chart.

program. The relevance of DOE's atmospheric chemistry activities not presently part of the ACP is discussed in Chapter 3.

The major carbon dioxide $\left(\mathrm{CO}_{2}\right)$ program within the ACRD is also administered separately from the ACP.

Scientific and administrative leadership for the ACP is effective. Appropriate scientific background in atmospheric modeling, an integrated view of atmospheric processes, and an appreciation of the role of laboratory studies and field measurements are evident. These field measurements, incidentally, offer the best opportunity to elucidate the underlying chemistry and physics of atmospheric phenomena and to provide the data required in testing model assumptions. Program leaders communicate well, publishing a monthly program newsletter and articulating program plans, strategies, activities, and accomplishments in briefing sessions to inter- 
TABLE 2.1 ACP Objectives in Understanding Air Chemistry Processes

\begin{tabular}{|c|c|c|}
\hline Primary Research & Laboratory & $\begin{array}{l}\text { Principal } \\
\text { Investigators }\end{array}$ \\
\hline $\begin{array}{l}\text { Dry-and wet-removal processes } \\
\text { Cloud physics modeling and } \\
\text { parameterization } \\
\text { Atmospheric photochemistry } \\
\text { Field data synthesis and interpretation }\end{array}$ & $\begin{array}{l}\text { Argonne } \\
\text { National } \\
\text { Laboratory }\end{array}$ & $\begin{array}{l}\text { J. Gaffney } \\
\text { I.-Y. Lee } \\
\text { D. Sistersor: } \\
\text { M. Wesely }\end{array}$ \\
\hline $\begin{array}{l}\text { Aerosol physics and chemistry } \\
\text { Gaseous- and aqueous-phase atmospheric } \\
\text { chemistry } \\
\text { Wet-removal processes } \\
\text { Field data interpretation }\end{array}$ & $\begin{array}{l}\text { Brookhaven } \\
\text { National } \\
\text { Laboratory }\end{array}$ & $\begin{array}{l}\text { P. Daum } \\
\text { L. Kleinman } \\
\text { Y.-N. Lee } \\
\text { M. Mazurek } \\
\text { L. Newman } \\
\text { J. Roberts } \\
\text { S. Schwartz } \\
\text { I. Tang }\end{array}$ \\
\hline Heterogeneous atmospheric chemistry & $\begin{array}{l}\text { Lawrence } \\
\text { Berkeley } \\
\text { Laboratory }\end{array}$ & T. Novakov \\
\hline Air-surface exchange processes & $\begin{array}{l}\text { National } \\
\text { Oceanic and } \\
\text { Atmospheric } \\
\text { Administration/ } \\
\text { Atmospheric } \\
\text { Turbulence and } \\
\text { Diffusion } \\
\text { Division }\end{array}$ & $\begin{array}{l}\text { D. Baldocchi } \\
\text { R. Hosker }\end{array}$ \\
\hline Dry-and wet-removal processes & $\begin{array}{l}\text { Oak Ridge } \\
\text { National } \\
\text { Laboratory }\end{array}$ & S. Lindberg \\
\hline $\begin{array}{l}\text { Wet-removal processes } \\
\text { Aircraft measurements of pollutant fate } \\
\text { Diagnostic modeling } \\
\text { Field data interpretation }\end{array}$ & $\begin{array}{l}\text { Battelle } \\
\text { Pacific } \\
\text { Northwest } \\
\text { Laboratory }\end{array}$ & $\begin{array}{l}\text { C. Berkowitz } \\
\text { K. Busness } \\
\text { T. Dana } \\
\text { R. Easter } \\
\text { S. Ghan } \\
\text { D. Luecken }\end{array}$ \\
\hline
\end{tabular}

agency panels and the Climate Research Committee. These communication skills will be needed to provide leadership and direction for ACP in a new phase of NAPAP activity. The program leadership must influence the direction of national laboratory-based programs and external grantee activities in order to respond to the atmospheric chemistry issues arising from an evolving National Energy Strategy (NES). As noted in Chapter 1, the NES 
will require effort on a wide (and as of this writing, only partially defined) variety of atmospheric chemistry problems. On all counts, a flexible and forward-looking leadership is necessary.

The DOE's external grants program for the ACP is scheduled to begin in FY 1991. The committee welcomes this program. It will be an important tool for broadening the ACP's capabilities and responses to new challenges. To direct these extramural resources to overall ACP goals, the program's central management-not the national laboratories-should administer this new activity. Initial funding for the program is fairly low, and, to have a substantial interaction and impact with the national laboratory portion of the program, it must grow.

\section{REVIEW OF CURRENT PROGRAMS}

\section{Laboratory Studies of Atmospheric Processes}

The DOE's laboratory studies of atmospheric processes have been concentrated in two major areas: multiphase chemistry, particularly processes relevant to oxidation of sulfur [S(IV)] and $\mathrm{NO}_{x}$, and atmospheric gas-phase photochemistry, especially related to $\mathrm{NO}_{x}$ and its ultimate fate in the troposphere.

\section{Multiphase Chemistry}

A decade ago knowledge of the chemistry occurring in/on aerosol particles, fogs, clouds, and raindrops was quite rudimentary. This lack of understanding of both the atmospheric chemistry involving the liquid and solid phases and the interaction of gases with these phases significantly impeded understanding of the formation and deposition of acids in the atmosphere.

In the past decade, laboratory studies by DOE scientists have made major contributions toward understanding multiphase atmospheric processes. DOE laboratories have been a leader, nationally and internationally, in defining the physical and chemical processes involved in the transport of gases to liquid droplets in the atmosphere (e.g., fogs, clouds, and particles) and their subsequent oxidation reactions in the liquid phase. These DOE studies include:

- assessment of mass transport limitations in the oxidation of S(IV) to $\mathrm{S}(\mathrm{VI})$, taking into account diffusion processes in both the gas and aqueous phases, interfacial mass transport, the gas-liquid equilibrium (i.e., Henry's law constants), and subsequent reactions in the liquid phase;

- definition of $\mathrm{SO}_{2}$ oxidation kinetics in the aqueous phase, both under laboratory conditions and using collected atmospheric samples; 
- assessment of the potential aqueous-phase oxidation of odd nitrogen compounds $\left(\mathrm{NO}_{y}\right)$ in the atmosphere, including transport into liquid droplets, Henry's law coefficients for a wide variety of nitrogenous species of atmospheric interest, and the kinetics of aqueous-phase oxidations;

- clarification of the atmospheric chemistry unique to marine areas, including the potential role of chloride ions in $\mathrm{NO}_{x}$ and $\mathrm{S}$ (IV) oxidation in particles and clouds;

- clarification of the physical and chemical properties of aerosols and how they change as a function of composition, relative humidity, and temperature;

- determination of mass accommodation coefficients for a variety of species of atmospheric interest; and

- development of new methods with the potential to measure such important species as hydrogen peroxide.

\section{Atmospheric Gas-Phase Photochemistry}

Gas-phase photochemistry has been the subject of intensive research for many decades. Interest in atmospheric photooxidation involving VOCs and $\mathrm{NO}_{x}$ dates back at least four decades to the discovery of photochemical smog. Although much remains to be learned in this area, it lacks the breadth of new research ideas and opportunities found in multiphase sulfur and nitrogen oxidations over the last decade. Perhaps as a result, the DOE has emphasized this area less, and the overall effort appears less focused than the multiphase studies. Nevertheless, researchers have made significant contributions in this area, and their expertise may prove increasingly valuable as the specific components of the NES develop.

DOE research in gas-phase reactions/photochemistry tends to concentrate on the atmospheric formation and fate of organic nitrogen compounds. Additional work in associated areas includes kinetics and the development of analytical methodology. Studies of the photochemistry and oxidation reactions of nitrogen compounds are essential for assessing the tropospheric fate of nitrogen oxides emitted from energy-related activities, particularly given the results of recent studies (some involving DOE scientists) indicating that not all the $\mathrm{NO}_{y}$ measured in field studies can be accounted for by the measured concentrations of individual nitrogenous compounds. Some areas studied are:

- development of procedures for synthesizing, purifying, handling, and measuring peroxyacetylnitrate (PAN) and other organic nitrates;

- measurement of the absorption cross sections of PAN and organic nitrates;

- clarification of the structure of PAN; 
- field measurements of PAN, peroxypropionylnitrates, alkyl nitrates, and associated species;

- extension of correlation methods for predicting gas-phase rate constants for homologous series of organic compounds to reactions of atmospheric interest; and

- development of methods to measure Cl-C6 carbonyl compounds.

\section{Summary}

The ACP laboratory component has made major contributions to understanding chemical and physical processes in the troposphere. Important questions have been addressed, new methodologies developed, and the results integrated into field and modeling efforts. In both areas of laboratory studies, multiphase and gas phase, the overall quality of the research has been commendable and, in some cases, outstanding. The research has led to timely publication of results in peer-reviewed journals.

\section{Fie $\because$ Measurements of Atmospheric Processes (Including MAP3S)}

The DOE field measurement activities fall into the following subject areas:

- precipitation chemistry network studies for monitoring (MAP3S);

- coordinated large-scale ground-based and aircraft studies of precipitation events associated with specific meteorological situations (e.g., frontal storms) and the development of models to encompass the results of such studies;

- aircraft studies of gas-phase and multiphase atmospheric chemistry that focus on oxidant formation;

- mass budget studies for sulfur, nitrogen, and carbon species; and

- advanced field measurement techniques.

For the most part, the mix of research programs is logical and consistent with the ACP's task. Field experiments are designed to aid in understanding the sources of energy-related combustion products, the meteorological factors that control their distribution in the atmosphere, the chemistry of these products in the atmosphere, and the wet and dry processes that remove them from the atmosphere.

Although these field programs are discussed separately from the airsurface exchange studies covered in Chapter 3, they are conceptually linked through understanding the source-sink functions at the earth's surface.

In this assessment, activities are discussed in terms of the five aforementioned categories. 


\section{Precipitation Network Studies}

The MAP3S network consists of nine stations located predominantly in the Northeast. Their basic protocol focuses on sulfur and nitrogen species (and associated species) in precipitation. These species are of interest to the National Acid Deposition Program (NADP), in which the MAP3S participated. However, the MAP3S is unique in the NADP; each station is associated with an independent research group engaged in a much broader research objective. Protocols at the stations can differ, including studies of trace metals, cloud droplet chemistry and physics, meteorology, organic acids, and dry deposition, for example.

The committee concludes that the fundamental program is sound and has no obvious faults. The quality and diversity of this research and monitoring clearly set the MAP3S apart from the many NADP monitoring activities that might be phased out, pending a 1992 decision on the fate of the NADP. The association of strong research programs with the network studies adds considerably to our understanding of the precipitation chemistry processes. This research is consistent with the ACP's current focus on multiphase processes. The committee also concludes that the interaction between DOE laboratories and various MAP3S field program groups (which are largely university based) is beneficial to DOE laboratories; it institutionalizes the cooperation between these laboratories and outside groups and ensures the influx of fresh ideas and flexibility in attracting expertise to specific problem areas.

Further, the continuous and highly time-resolved measurement protocols observed by network members could be useful in assessing the impact on $\mathrm{SO}_{2}$ emissions mandated in the 1990 amendments to the Clean Air Act.

\section{Coordinated Large-Scale Studies of Precipitation Events}

It is clear that cloud and precipitation processes are critical to the transport, transformation, and removal of combustion products from the atmosphere. It is also clear that knowledge in this area is woefully inadequate. This deficiency is partly due to the complexity of the process and the difficulty of studying cloud processes that are inherently dynamic and ephemeral. For these reasons, it is appropriate that such programs reside in the ACP.

On the basis of its limited review, the committee concludes that the general outline of the field measurement program is satisfactory and that the capabilities of the researchers are adequate. However, the committee is concerned about the specific example presented in the frontal boundary study program. The synoptic situation was extremely complex; consequently, the results are difficult to interpret. The committee believes that this prob- 
lem could have been anticipated in advance of the experiment on the basis of the synoptic situation and that the research group should have waited for a better synoptic situation. We hope that the other synoptic events to be studied will be more readily amenable to interpretation.

The close cooperation between the field research program and the modeling effort is commendable [specifically, the Regional Acid Deposition Model (RADM) scavenging module development]; the modeling objective is highly appropriate for the ACP mission.

\section{Aircraft Studies}

The overall objectives of the aircraft program and the strategy of the operation appear to be satisfactory. Because the committee's review was brief, we cannot comment on the specifics of the experimental design or the instrumental techniques. However, the committee has reservations about the simplistic interpretation of the results of the field study (in Ohio, June 1987) presented. This particular program might benefit from a closer interaction with outside photochemical modeling groups in both experiment design and data interpretation phases to ensure maximum utility of the data.

\section{Mass Budget Studies}

The mass budget studies of energy-related anthropogenic species are important from several standpoints. Most obvious is the need to follow trends in emissions. An equally important task is providing data for the various large-scale atmospheric chemistry models. These models are becoming increasingly sophisticated in meteorology and chemistry, and they are incorporating higher spatial resolutions; hence, reliable and accurate data source strengths and distributions are essential.

Although trends in emissions from energy systems are not an ACP concern, other DOE elements should be charged with charting these trends to guide policy formulation.

The priority given to studies of $\mathrm{NO}_{x}$ production by storm-related lightning is not clearly justified. It is important to understand the relative strengths of anthropogenic and natural sources of $\mathrm{NO}_{x}$, especially lightning, but this problem is exceedingly complex, and its resolution will require the efforts of many scientists drawn from many disciplines. The current DOE effort is too small to solve this problem. The presentation made to the committee suggests that DOE investigators might not be fully aware of this problem's boundaries; simple mass budget calculations and historical data argue against their stated flux estimates, which are probably high by more than an order of magnitude. The committee concludes that the resources allocated to the 
lightning study would be better spent on research that is more closely allied with the ACP mission.

Measurement of carbonaceous aerosols (and associated species) is important in the assessment of the budgets of energy-derived species. Carbonaceous aerosols are also important to understanding visibility. The committee is satisfied that this is a relevant activity and is impressed with how the program is being carried out.

\section{Advanced Field Measurement Techniques}

The ACP must have the capability to explore the use of advanced instrumentation for measuring energy-related species in the atmosphere. The presentation to the committee focused on the use of an atmospheric pressure chemical ionization (APCI) tandem mass spectrometer (MS/MS) in the laboratory aboard the G-1 research aircraft. Clearly, an APCI-MS/MS would be a great boon to atmospheric chemistry research because of its potential for high sensitivity, broad species coverage, and high data throughput. The committee supports such an effort. Nonetheless, we caution that it will take a lot of work to develop measurement procedures for this instrument and the potential for artifacts and other problems is high. The investigators appear to be aware of these pitfalls.

\section{Air-Surface Exchange Processes: Measurements and Models}

The DOE has been studying surface exchange processes for almost two generations. The ACP's roots are found in research begun in the 1950s to quantify the deposition of radioactive substances from atmospheric nuclear tests. More recently, interest in DOE deposition research was rekindled by the role of deposition in acid rain. Much of this acidic material is generated by industry's combustion of fossil fuel. Thus, the research fell within the traditional DOE purview.

In this regard, a key unknown is the role of dry deposition, which is responsible for approximately one-half the deposition of acidic material in the United States. To quantify the dry deposition of strong mineral acids, nitric acid, and sulfuric acid, the DOE's program was initiated through the NAPAP to study the deposition processes involving acidic material. The DOE assumed the lead for research aimed at understanding the processes responsible for atmospheric deposition of acid material to surfaces, the quantification of those processes, and the development of parametric representations of deposition for incorporation into models.

To date, activities have tended to focus on terrestrial deposition of acidic gases and aerosols, their precursors, and ozone. This activity, as described, contains three major efforts: a study of canopy interactions in the deposi- 

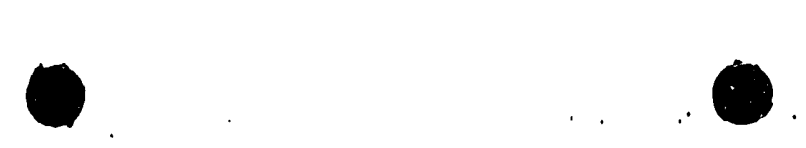

tion process, canopy micrometecrology, and dry deposition processes research as applied to deposition over the continental land masses. To accomplish this research, the program developed and applied a variety of measurement techniques, including surface analysis and atmospheric flux methods. In addition, sophisticated models were developed to understand transport through forest canopies and other complex surface interception. DOE scientists have worked closely with the chemical modeling community to provide deposition velocities for use in chemical models; they have developed procedures for efficiently transferring this information in usable form.

The ACP is a leader in the international scientific community for its development and use of surface analysis methods and their use in measuring dry deposition. It has excelled in developing methods to study surface exchange using state-of-the-art micrometeorological techniques for trace substance exchange and in interpreting the results, particularly as they relate to the exchange process in forest canopies. The ACP has also excelled in developing dry deposition modules for use in regional and global chemical/ dynamical models.

\section{Modeling and Analysis of Atmospheric Processes}

ACP modeling activities began with the need to understand the processes underlying acid deposition within ecologically sensitive regions of North America. Modeling now includes description of the hemispheric distribution and transport of gaseous- and condensed-phase materials. This complex area of atmospheric science has many variables, and comparing theory with experiment is often difficult.

Some progress has been made with parameterization of individual physical processes. Precipitation rates are reasonably well simulated, and estimates can be made of both the vertical transfer of pollutants in convective cloud cells and the actinic flux within cloud systems. Global models of atmospheric chemistry will benefit from this work. Detailed prediction of the precipitation of chemical species by a single storm event is extremely difficult; the committee questions whether this type of modeling activity is the most effective use of scarce resources, considering the complexities of air motion within frontal cloud systems.

Inclusion of cloud chemistry research, which has been part of the DOE program, in deposition modeling on regional and global scales is greatly improving quantitative predictions of acidic pollutant deposition in areas remote from sources. The program, Processing of Emissions by Clouds and Precipitation, has made considerable progress in this area, sometimes challenging the results of others. Some aspects of the calculated deposition 
patterns for sulfate, particularly the western extension of European emissions, differ from similar calculations made at Stockholm University.

Overall, ACP modeling activities have made notable advances in understanding the large-scale influences of clouds on atmospheric chemical phenomena. They are a significant reservoir of regional- and continental-scale modeling experience. 


\section{Recommendations for Revising and Strengthening the DOE Atmospheric Chemistry Program}

\section{FOCUS ON FUTURE EFFORTS}

Given the unknown formulation and path of the National Energy Strategy (NES), what specific issues will the Atmospheric Chemistry Program (ACP) be required to address? Any or all of the topics outlined in Chapter 1 may require serious attention. Some issues that committee members think the ACP should consider in the near future are outlined below.

\section{Climatic Impact of Sulfate Aerosols}

Recent laboratory, field, and modeling efforts of groups involved in the ACP focused largely on multiphase atmospheric chemistry. Although the formation and deposition of acidic materials received special emphasis, the core of scientific knowledge concerns the simultaneous physical and chemical processes involved with the condensed phases of the atmosphere. Also emphasized were the processes that create water-soluble mass in the atmosphere, particularly sulfate and nitrate ions. The difficult problem of new particle generation from gases (e.g., by heteromolecular nucleation) has not been a key topic, but work on the chemical reactions in cloud water and aerosol surfaces has been studied extensively.

It is now recognized that the same sulfate associated with acidic precipitation and energy production has two physical effects of first-order importance to understanding global climate change. Sulfate aerosol particles reflect some incident solar radiation to space, thereby reducing solar irradiance at the ground and cooling the earth. Some of these same sulfate par- 
ticles act as cloud condensation nuclei (CCN), the number of which help determine cloud albedo (i.e., reflectivity for sunlight).

The heat balance of the earth is sensitive to the concentration of $\mathrm{CCN}$, such that a change of only \pm 30 percent results in a global temperature change of $\pm 1^{\circ} \mathrm{C}$ (Twomey et al., 1984; Charlson et al., 1987; Schwartz, 1988). However, there are major gaps in understanding the degree to which the $\mathrm{CCN}$ number concentration is influenced by changes in the mass concentration of sulfate (e.g., due to the combustion of fossil sulfur along with fossil carbon). There is no doubt that $\mathrm{CCN}$ number concentrations are increased by anthropogenic sulfate (and thus clouds are made whiter), but quantitative evaluation is possible only in limited cases (Coakley et al., 1987).

Quantitative assessment of the change in heat balance due to the hemispheric or globally distributed background aerosol, often implicitly assumed to be natural in origin, indicates a cooling of the planet of $2^{\circ}$ to $3^{\circ} \mathrm{C}$ (Coakley et al., 1983). Assessment of the regional impacts of the anthropogenic sulfate haze by Ball and Robinson (1982) indicated an annual average loss of solar irradiance of 7.5 percent over a large area of the eastern United States. However, it has only recently been recognized that the hemispheric impact of anthropogenic sulfate, largely from energy production, is around half the $2^{\circ}$ to $3^{\circ} \mathrm{C}$ cooling or around $-1 \mathrm{~W} / \mathrm{m}^{-2}$ in terms of heat balance (Charlson et al., 1990). Although this estimate has uncertainty of about a factor of 2 , it is comparable in magnitude but opposite in sign to the current greenhouse forcing by anthropogenic carbon dioxide $\left(\mathrm{CO}_{2}\right)$ of $+1.5 \mathrm{~W} / \mathrm{m}^{-2}$. Thus, it is imperative that the Department of Energy (DOE) recognizes this climate impact of anthropogenic sulfate and ensures that it is studied and fully understood as a factor in global change. Earlier work on the climatic effect of aerosols lacked an understanding of and emphasis on the multiphase atmospheric chemical processes that produce and control sulfate aerosol amounts and properties. The special capability of the ACP with regard to these exact topics makes it uniquely well suited for the task.

\section{Indoor Air Chemistry Associated with Energy Use}

The committee was told that this area apparently falls under another DOE division. However, some DOE scientists with backgrounds in atmospheric chemistry are working in the Indoor Air Environment Program (IAEP) at the Lawrence Berkeley Laboratory's (LBL) Applied Science Division. They are applying methodology and chemistry that could be useful in the ACP. Although published literature on indoor air pollution has often focused on determination of the types and concentrations of species present in indoor air environments, recent studies suggest that reactions of $\mathrm{NO}_{x}$ (e.g., on surfaces) might be occurring that are similar to those observed in 
smog chambers and that are believed to be present $i$ - the atmosphere as well. Inclusion of the expertise currently available in ne IAEP in the ACP, or at least improved interaction between the programs, would prove mutually beneficial.

\section{Assessment of the Effects of Control Strategies on Air Quality}

The ACP may be called on to assiss the effectiveness of control strategies. For example, data from the MAP3S network, with its time-resolved sampling, would be useful in assessing changes in : zid deposition due to reductions in sulfur emissions mandated by the new Clean Air Act.

A second example involves oxygenated fuels that are currently used in some areas and v/hose distribution is expected to increase. Although they have been promotyd for improving air quality in several ways, including lowering carbon monoxide $(\mathrm{CO})$ and in some cases ozone $\left(\mathrm{O}_{3}\right)$, a methodology to test their effectiveness under conditions of real use is not well developed. ACP scientists, especially those with expertise in gas-phase photochemistry, could contribute significantly in this area.

\section{RECOMMENDATIONS FOR NATIONAL LABORATORY PKOGRAMS}

\section{Laboratory Studies of Atmospheric Processes}

DOE laboratories have developed unique expertise in experimental studies of the transport of gases to and across interfaces and of reactions in the condensed phase. During the National Acid Precipitation Assessment Program (NAPAP), these studies were applied primarily to the oxidation of $\mathrm{S}$ (IV) and $\mathrm{NO}_{x}$ in the liquid phase; the techniques and knowledge can be extrapolated to a variely of tropospheric processes traditionally called heterogeneous reactions.

Research on reactions in and on the surfaces of particles in the atmosphere has been difficult. The goal of obtaining quantitatively, and even qualitatively, reproducible results has proven elusive. However, with the discovery five years ago of the Antarctic ozone hole, and the role of gascondensed phase reactions in this rapid destruction of stratospheric ozone, there is renewed interest in develcping methods to study the behavior of particles in both the stratosphere and the troposphere and their associated gas-solid and gas-liquid interactions.

The expertise on multiphase processes both physical and chemical, developed in DOE laboratories during the NAPAP is a unique and highly capable resource for examining reactions in and on the surfaces of bcth liquids and solids in the troposphere. For example, the single-particle levi- 
tation methodology combined with Raman spectroscopy currently being explored at Brookhaven National Laboratory (BNL) is potentially a particularly powerful method for obtaining insights not only into the chemical composition of particles but also into such parameters as vapor pressures of low-volatility compounds.

Other areas of direct importance to the DOE's mission that will benefit from existing ACP expertise include the role of solid and liquid aerosols in the uptake or release of species in the troposphere, their role as potential catalysts for tropospheric reactions, and their contributions to the radiation balance. Given the global distribution of pollutants associated with energy production, processes relevant to both continental and oceanic aerosols must be considered.

In the area of gas-phase chemistry/photochemistry, a predominant theme in $\mathrm{ACP}$ research has been the fate of tropospheric $\mathrm{NO}_{x}$. Laboratory and field programs, for example, have cooperated in developing analytical methodologies for PAN and other organic nitrates and in applying the techniques to measuring these compounds in tive troposphere. This cooperation, an important strength of the program, is strongly encouraged in future work.

Shorter-term energy-associated issues on which the ACP may be asked to provide scientific information and advice to policymakers include:

- the generation and atmospheric fate of airborne toxics associated with energy production and

- the use of alternate fuels (for transportation, heating, and power generation) and their implications for local and regional photochemical air pollution as well as global atmospheric chemistry.

DOE scientists, particularly those in the gas-phase chemistry program, are capable of addressing such issues; some have already begun. Focusing and perhaps enhancing these efforts should help anticipate needs from the regulatory and policymaking sides of government.

In future ACP efforts, the close coordination that generally exists among ACP laboratories should be encouraged and strengthened. For example, the aerosol and cloud chemistry work at $\mathrm{L} B \mathrm{~L}$, the multiphase studies at BNL, and the development of new analytical techniques for reactive organics at Argonne National Laboratory and BNL may particularly benefit from continued and increased cooperation. Geographical separation of these sites requires special effort to ensure sufficient interaction for successful collaboration.

\section{Field Measurements of Atmospheric Processes}

As stated in the assessments of Chapter 2, the committee finds the program quite satisfactory. Some relatively minor suggestions for improve- 
ments are made in Chapter 2. In the remainder of this chapter, the focus is on issues related specifically to the Multi-State Atmospheric Power Production Pollution Study (MAP3S).

The committee has strong feelings that the MAP3S fulfills an important function. It is unlike many National Acid Deposition Program (NADP) subprograms in that monitoring is a relatively minor component. An important distinction is that the MAP3S follows a protocol of daily sampling, whereas other NADP stations sample weekly. Because of the daily protocol, MAP3S data can be used to develop a precipitation climatology; consequently, it will be possible to relate precipitation chemistry to meteorology. Such data will be invaluable for developing and testing transport and deposition models. Model testing can be done only with daily (or more frequent) precipitation data, such as the data obtained in the MAP3S. It would be ironic (and extremely wasteful) if data collection were to stop now, when development of sophisticated meteorology/chemistry models is finally producing meaningful results. MAP3S network data will be useful for planning intensive field experiments; the stations could provide valuable data in support of such experiments.

The MAP3S's network should be integrated into the evolving global precipitation network. A large and sophisticated precipitation measurement network in Europe (the Cooperative Program for Monitoring and Evaluation of the Long-Range Transmission of Air Pollutants in Europe) operates in a daily (or more frequent) mode that would complement MAP3S activities. Similarly, the Atmosphere/Ocean Chemistry Experiment in the North Atlantic and several sampling networks in Canada follow a daily precipitation protocol. All these networks will provide data for testing long-range transport models under development. For example, the Regional Acid Deposition Model (RADM) is being extended across the North Atlantic, and, by the end of the 1990s, RADM-like models should be available for the entire northern hemisphere. Without MAP3S-like data, such models would be seriously handicapped.

The MSP3S is also important to atmospheric chemistry because of its exploratory research at a growing number of sites. Activities include development and testing of new sampling protocols in atmospheric and precipitation chemistry.

Because of the importance of MAP3S-like programs to national interests and to evolving international global change activities, the committee recommends that the DOE initiate discussions among relevant U.S. government agencies regarding the role of network activities in precipitation and atmospheric chemistry studies. The agencies should define the objectives of such networks and their organization and support mechanisms. This examination may require the interested parties to abandon the concept of regionally discrete studies and shift focus to include larger scales. This change 
may in turn require a reassessment of agency roles vis-à-vis national priorities and the global perspective. DOE should continue to support the MAP3S until a MAP3S program, or something similar, is institutionalized in the federal structure.

In accordance with growing awareness of the importance of multiphase processes, the MAP3S's protocol should be expanded to incorporate measurements of gases and aerosols that are necessary for understanding precipitation chemistry. Consideration should also be given to initiating measurements of species that are relevant to climate research.

\section{Air-Surface Exchange Processes: Measurements and Models}

The following activities should be continued and expanded by one or more of the activities that were reviewed:

- The ACP should continue development and application of surface analysis methods to quantify aerosol, sulfur, and nitrogen deposition to forests and other complex terrains. Deposition under these conditions is an extensive and complex phenomenon requiring continued research.

- The program should develop models and field methods for many trace substances. Mercury and other trace metals are good initial candidates. A rigorous intercomparison of surface analysis methods with micrometeorological techniques should be undertaken. ACP participants should be encouraged to cooperate with other agencies using fast-response detectors for $\mathrm{NO}_{x}$ odd nitrogen compounds $\left(\mathrm{NO}_{y}\right)$ and to develop fast-response detectors for nonmethane hydrocarbons that can be used to measure atmosphere-surface exchange of these compounds.

- The capability to measure and model $\mathrm{CO}_{2}$ exchange should be pursued to establish the terrestrial exchange of this radiatively important trace compound. An understanding of turbulent mixing above forest canopies should be developed to determine the rate of transport of trace gases to and from the atmosphere. This knowledge should contribute to more accurate estimates of spatially averaged fluxes.

- The development of deposition modules for atmospheric models should be continued in cooperation with the agencies responsible for this work. These modules are key to development of reliable regional and global models that the ACP employs. The development of reliable methods, such as eddy accumulation, that use less sophisticated chemical detectors to measure trace gas exchange should be continued.

\section{Modeling and Analysis of Atmospheric Processes}

Future modeling activities should reflect the ACP's new emphasis away from purely regional considerations to the impacts of continental emissions 
on the global atmosphere or at least the atmosphere of the northern hemisphere, including the Arctic.

Specifically, the capability should be developed to model changes in the chemical composition of air leaving the United States and spreading over the North Atlantic Ocean, with a particular emphasis on aerosol content and its ability to affect cloud droplet size distributions. The impact of North American nitrogen oxide and hydrocarbon emissions on ozone production throughout the northern hemisphere should also be considered.

Global aspects of the cloud modeling studies should therefore be emphasized and combined with more conventional chemical modeling studies of the global atmosphere, such as those being conducted at the Lawrence Livermore National Laboratory (LLNL). The separate modeling groups should develop strong communication links among themselves and with others in the international modeling community. It is now realized that clouds are a significant factor in the chemistry and transport of pollutants in the lower atmosphere and have major impacts on the earth's climate. The DOE modeling group, with its diverse skills in parameterization of individual cloud processes, quantification of cloud chemistry of sulfur compounds, and modeling impacts of increased anthropogenic emissions of $\mathrm{NO}_{x}$ on tropospheric chemistry, should be able to make a substantial contribution to theoretical studies necessary in the International Global Atmospheric Chemistry (IGAC) project of the International Geosphere-Biosphere Program (IGBP) and other international programs.

These studies should be carried out with considerable attention to sensitivity analysis in order to identify aspects of the input data and parameterizations that most influence the model output. In addition, a strong link between theoretical studies and experimental programs should be developed, with guidance and insight exchanged among scientists engaged in both aspects. The theoretical group within the ACP should try to use existing data (such as that provided by the MAP3S precipitation network) in developing and testing their models. It is particularly important that significant effort be spent testing models against relevant field data. Without close checks on model outputs, application to the design of control strategies could be misleading.

\section{INTRAPROGRAM INTERACTIONS}

ACP elements, now geographically dispersed, will become more so with the addition of extramural grantees. The committee believes the new extramural program can significantly strengthen the ACP by including leading atmospheric scientists from academic and private sector laboratories. It is important, however, that all segments of the ACP be encouraged to communicate frequently and to plan and execute synergistic research activities. 
ACP personnel from the national laboratories and grantee/contractor institutions should meet regularly to facilitate information exchange and scientific collaboration. Future plans should also be reviewed to avoid undesirable duplication and to encourage cooperation.

DOE policy experts should be encouraged to attend ACP meetings to help couple the program to the NES.

\section{P ITERACTIONS WITH OTHER FEDERAL AND INTERNATIONAL PROGRAMS}

\section{Other DOE Programs}

Two major areas of endeavor in the ACP are highly relevant to research in global climate change. Although other DOE programs address the $\mathrm{CO}_{2}$ issue, it is necessary to consider the atmospheric chemistry of reactive greenhouse gases. In addition, as discussed in Chapter 3, the ACP expertise in multiphase atmospheric chemistry is particularly relevant to studies of the effects of aerosol particles on solar radiation and cloud albedo. Both these areas are under study with different complementary perspectives and foci in other governmont agencies and government-sponsored projects. The two DOE activities are the $\mathrm{CO}_{2}$ program and the Atmospheric Radiation Measurement (ARM) program. How will the ACP aerosol/climate research be coordinated? Some ACP personnel are active in ARM planning, but the committee is unaware of any attempt to coordinate efforts in order to identify important gaps and provide needed communication. DOE leadership should address this matter.

Subsequent to its review, the committee learned that several research projects involving formation chemistry, optical properties, and cloud condensation properties of aerosols were begun as part of the ARM program during FY 1990. The committee questions the wisdom of administratively separating these programs from scientifically similar activities currently within the ACP.

\section{Other U.S. Programs}

The ACP is a leader in multiphase atmospheric chemistry, the field study of cloud chemistry, the development of techniques to measure and model dry deposition, and the monitoring of wet deposition. These activities are given high priority in the planning document for the U.S. Global Tropospheric Chemistry Program (GTCP). Comprehensive plans for the U.S. GTCP were developed by more than 100 U.S. and foreign atmospheric chemists, and they have been reported in detail (OIES, 1986). The committee adopted these plans as the blueprint for U.S. global tropospheric chem- 
istry research. GTCP elements are currently supported by the National Science Foundation, the National Oceanic and Atmospheric Administration, and the National Aeronautics and Space Administration. The committee believes that coordination of DOE activities with the GTCP is essential.

Moreover, the ACP incorporates elements that are fundamental to the U.S. program aimed at understanding the factors that contribute to global change and at developing a capability to predict it (OSTP, 1989). Its chemistry capability is a key component in current national programs aimed at understanding global climate change, global atmospheric chemistry, and biosphere-atmosphere exchange. Many of these capabilities are unique to the DOE. Failure to support them would substantially lessen momentum in several fundamental national and international scientific undertakings.

\section{International Programs}

The recently established IGAC, under the international Commission on Atmospheric Chemistry and Global Pollution (a commission of the International Association of Meteorology and Atmospheric Physics) has several projects to which the United States is expected to contribute. The ACP is a logical U.S. focal point for several IGAC projects. The North Atlantic Regional Experiment, for example, has objectives similar to the ACP's, allowing extension of the continental focus over the entire North Atlantic region. Another example is a project concerned with the chemical and physical evolution of $\mathrm{CCN}$ as controllers of cloud properties. As these projects develop, it will be appropriate to foster communication with ACP scientists to ensure that U.S. capabilities are integrated in international efforts. Activities supporting the IGAC will contribute simultaneously to U.S. research program efforts. 


\section{4}

\section{Conclusions and Recommendations}

\section{CONCLUSIONS}

In this chapter the committee concisely states the major conclusions it has drawn from the presentations and discussions comprising its review.

1. Atmospheric chemistry is vital to the Department of Energy's (DOE) mission of formulating and implementing a National Energy Strategy (NES).

2. The current Atmospheric Chemistry Program (ACP) is well balanced, containing strong laboratory, field measurement, and modeling elements, and it is capable of performing comprehensive atmospheric chemistry studies of the type required to support an NES.

3. The DOE's grouping of the separate elements of atmospheric chemistry research within the ACP is well motivated and welcomed by the atmospheric chemistry research community. Other national laboratory program elements might well be added to the ACP.

4. The current ACP components have made important scientific contributions to the National Acid Precipitation Assessment Program (NAPAP), and the ACP has the potential to continue to contribute significantly to problems of national interest if it is maintained, coordinated, and supported.

5. The general quality of the ACP elements is commendable and, in some instances, outstanding.

6. In particular, the ACP's multiphase capability is a national asset that represents a significant portion of our national capability in this important area.

7. The surface exchange components of the ACP have a strong interna- 
tional reputation, and they have made significant contributions to the quantification of atmospheric gas and particle deposition.

8. The ACP was created in 1990 as the first phase of the NAPAP was ending; an opportunity now exists to establish important long-term goals for the program in concert with new NAPAP objectives.

9. Many aspects of the ACP's multiphase chemistry research are important to understanding the formation, growth, and removal of cloud condensation nuclei and atmospheric aerosols. They thus contribute to understanding the radiative properties of the atmosphere and, concomitantly, climate change.

10. The research required to understand all aspects of atmospheric chemistry and atmosphere-surface exchange is beyond the resources of any single government agency; it requires interagency and international cooperatior: Requirements imposed by the NES will almost certainly necessitate strengthening ACP personnel ties to ongoing research programs sponsored outside the DOE.

\section{RECOMMENDATIONS}

Recommended budgetary and administrative actions for sustaining and strengthening the ACP are as follows:

1. The DOE should continue to fund a well-balanced and highly capable ACP with enhancement of present activities when appropriate.

2. The ACP should be capable of dealing with a wide variety of air quality issues that may arise as a consequence of the NES, including local and regional photochemical pollution, airborne toxics, indoor air quality, acid deposition, atmospheric turbidity, and visibility. The full range of temporal and spatial scales implied by the NES should be included.

3. The impacts of aerosol particles and cloud microphysical processes on the earth's radiation balance may be of comparable importance to impacts of anthropogenic carbon dioxide $\left(\mathrm{CO}_{2}\right)$. Because the relevant DOE expertise on the formation, growth, and fate of atmospheric particles resides in the ACP, this expertise should be linked strongly to other DOE research efforts in atmospheric radiative transfer and climate change [e.g., the Atmospheric Radiation Measurement (ARM) program] and supported accordingly.

4. Opportunities to coordinate $A C P$ activities with ongoing national and international tropospheric chemistry programs should be identified and implemented, particularly when strong capabilities in multiphase processes and surface exchange are required.

5. The ACP's regional-, continental-, and global-scale modeling capabilities need to be strengthened and better integrated with its other components. Incorporation of ongoing tropospheric modeling programs at the 
Lawrence Livermore National Laboratory (LLNL) into the ACP may be a logical response to this need.

6. The ACP should consider including the Indoor Air Environment Program (IAEP) of the Lawrence Berkeley Laboratory (LBL) or, at a minimum, improving interaction between the two programs.

7. The MAP3S network of deposition and precipitation process research sites should be maintained and enhanced by the DOE until a multiagencysupported network of national sites with comparable or increased capabilities is designed and implement

8. Regular meetings of ACP na: al laboratory and grantee/ contractor personnel should be held to facilitate collaboration, exchange of information, and review of proposed efforts. At least some of the meetings should include personnel from DOE's policymaking areas to ease the transfer of information between science and policy. 


\section{References}

Ball, R.J., and G.D. Robinson. 1982. The origin of haze in the central United States and its effect on solar irradiation. J. Appl. Meteorol. 21:171-188.

Charlson, R.J., J.E. Lovelock, M.O. Andrae, and S.G. Warren. 1987. Oceanic phytoplankton, atmospheric sulfur, cloud albedo, and climate. Nature 326:655-661.

Charlson, R.J., J. Langner, and H. Rodhe. 1990. Sulphate aerosol and climate. Nature 348:22.

Coaklcy, J.A., Jr., R.D. Cress, and F.B. Yurevich. 1983. The effect of tropospheric aerosols on the earth's radiation budget: A parameterization of climate models. J. Atmos. Sci. 40:116-138.

Coakley, J.A., Jr., R.L. Bemstein, and P.A. Durkee. 1987. Effect of ship-stack effluents on cloud reflectivity. Science 237:1020-1022.

Graedel, T.E. 1978. Chemical Compounds in the Atmosphere. New York: Academic Press.

Kramlich, J.C., J.A. Cole, J.M. McCarthy, W.S. Lanier, and J.A. McSorley. 1989. Mechanisms of nitrous oxide formation in coal flames. Combust. Flame 77:355. 384.

National Academy of Sciences (NAS). 1981. Indoor Pollutants. Washington, D.C.: National Academy Press.

National Academy of Sciences (NAS), 1990. Haze in the Grand Canyon. Washing. ton, D.C.: National Academy Press.

Office for Interdisciplinary Earth Sciences (OIES). 1986. Global Tropospheric Chemistry: Plans for the U.S. Research Effort. OIES Report No. 3. Boulder, Colo.: OIES.

Office of Science and Technology Policy (OSTP), Committee on Earth Sciences. 1989. Our Changing Planet: A U.S. Strategy for Global Change Research. Washington, D.C.: OSTP. 
Office of Technology Assessment (OTA). 1989. Catching Our Breath-Next Steps for Reducing Urban Ozone. Washington, D.C.: OTA.

Rotty, R.M., and C.D. Masters. 1985. Carbon dioxide from fossil fuel combustion: Trends, resources, and technological implications. In: Atmosphere Carbon Dioxides and the Global Carbon Cycle. Report DOE/ER-0239. Washington, D.C.: U.S. Department of Energy.

Ryan, P.B., M.L. Soczek, R.D. Treitman, and J.D. Spengler. 1988. The Boston residential $\mathrm{NO}_{2}$ characterization study. II. Study methodology and population concentration estimates. Atmos. Environ. 22:2115-2125.

Samet, J.M., M.C. Marbury, and J.D. Spengler. 1987. Health effects and sources of indoor air pollutants. Part 1. Am. Rev. Respir. Dis. 136:1486-1508.

Schwartz, S.E. 1988. Are global cloud albedo and climate controlled by marine phytoplankton? Nature 336:441-445.

Twomey, S., M. Piepgrass, and T.L. Wolfe. 1984. An assessment of the impact of pollution on cloud albedo. Tellus 36B:356-366.

U.S. Department of Energy (DOE). 1990. Interim Report-National Energy Strategy. Report No. DE90-009000. Washington, D.C.: DOE.

U.S. Environmental Protection Agency (EPA). 1990. Proceedings of the International Workshop on Methane Emissions from Natural Gas Systems: Coal Mining and Waste Management Systems. Washington, D.C.: EPA.

World Meteorological Organization (WMO). 1989. Scientific Assessment of Stratospheric Ozone: 1989. WMO/GORMP Report No. 20. Geneva: WMO. 


\section{Acronyms}

$\begin{array}{ll}\text { ACP } & \text { Atmospheric Chemistry Program } \\ \text { ACRD } & \text { Atmospheric and Climate Research Division, OHER } \\ \text { APCI } & \text { Atmospheric pressure chemical ionization } \\ \text { ARM } & \text { Atmospheric Radiation Measurement (program) } \\ \text { RNL } & \text { Brookhaven National Laboratory } \\ \text { CCN } & \text { Cloud condensation nuclei } \\ \text { DOE } & \text { Department of Energy } \\ \text { GTCP } & \text { Global Tropospheric Chemistry Program } \\ \text { IAEP } & \text { Indoor Air Environment Program } \\ \text { IGAC } & \text { International Global Atmospheric Chemistry (project) } \\ \text { IGBP } & \text { International Geosphere-Biosphere Program } \\ \text { LBL } & \text { Lawrence Berkeley Laboratory } \\ \text { LLNL } & \text { Lawrence Livermore National Laboratory } \\ \text { MAP3S } & \text { Multi-State Atmospheric Power Production Pollution Study } \\ \text { MS } & \text { Mass spectrometer } \\ \text { NADP } & \text { National Acid Deposition Program } \\ \text { NAPAP } & \text { National Acid Precipitation Assessment Program } \\ \text { NES } & \text { National Energy Strategy } \\ \text { OHER } & \text { Office of Health and Environmental Research } \\ \text { RADM } & \text { Regional Acid Deposition Model }\end{array}$




\section{Chemical Symbols and Abbreviations}

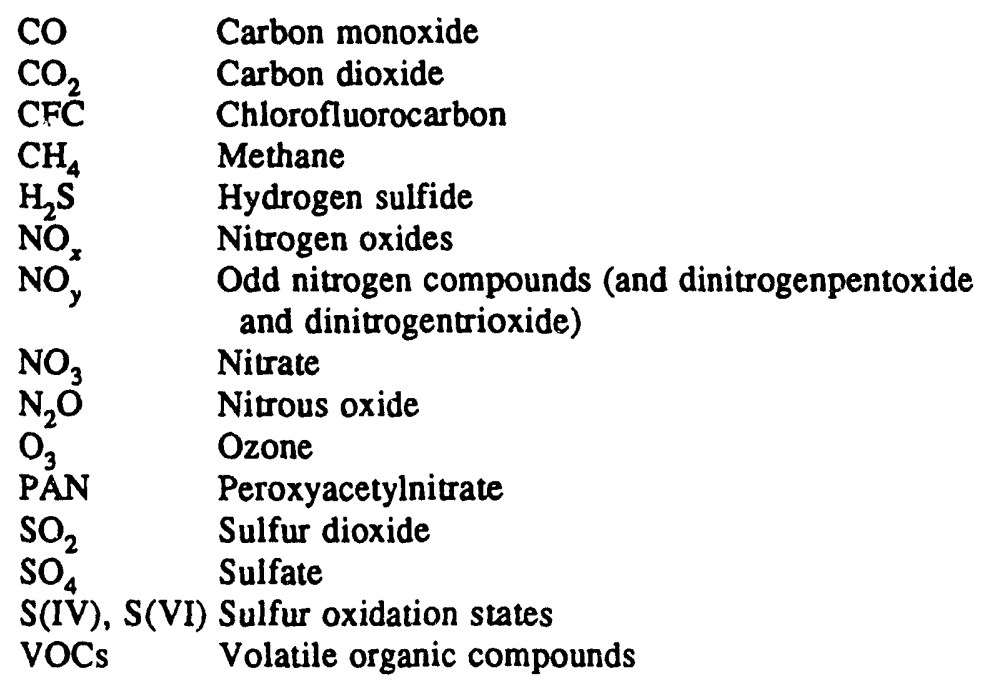




\section{Appendix}

\section{Questions Posed for the Atmospheric Chemistry Program Review}

\section{TECHNICAL PRODUCTIVITY AND LABORATORY CAPABILITY}

- What is your judgment of the technical competence and quality of the work described in the presentations?

- What areas of capability and expertise reside in the Department of Energy (DOE) laboratories that will be particularly valuable in supplying the information requirements of the National Energy Strategy (NES)? How can these resources be most effectively complemented within the scope of the Atmospheric Chemistry Program's (ACP) University Grants Program?

\section{PROGRAM LEADERSHTP AND ORGANIZATION}

- A strong and obvious ACP emphasis is placed on fulfilling the (anticipated) requirements of the NES. Is this appropriate? Do you have any suggestionz for improving the ACP's accountability and responsiveness in this respect?

- Is the ACP technical director providing the focus and leadership Semanded by the program? Are the program's organization and marching plan appropriate? Do you have any suggestions for improvement?

- The ACP is composed of DOE laboratories that are located throughout the country, and a similar geographical distribution of extemal contractors is anticipated. Does the committee see any large problems associated with this dispersion of contributors? Do you have any -uggestions for improving communications and efficiency in this respect?

- With the exception of university Multi-State Atmospheric Power Pro- 
duction Pollution Study (MAP3S) participants, pre-ACP subcontractors have been funded directly by DOE laboratories. With the onset of the ACP's University Grants Program, most such future funding will flow directly from DOE headquarters. Is this arrangement appropriate? Does the August 3 solicitation provide the proper scope for external research under the ACP? Do you have any guidance for the selection of proposals submitted inder this solicitation? Do you have other suggestions in this context?

\section{PLANS FOR THE FUTURE}

- Are the plans for future scientific work, as articulated in the presentations, appropriate for maximizing scientific productivity in the context of the NES, the capabilities of the laboratories, and the existing state of scientific understanding?

- The DOE has taken the position that air and precipitation quality monitoring is not within its charter. In view of this, does the MAP3S network fall into this category, and should the DOE discontinue its associated funding? If not, should the MAP3S be assumed by some other agency? Which one(s)? Is there a need for a multiagency group to coordinate air and precipitation quality monitoring in the United States?

- Several joint field studies involving atmospheric pollutant fate are currently in the planning stages. Should the ACP participate in any of these? Which ones?

- Should the ACP take an active role as a participant in the evolving Global Tropospheric Chemistry Program (GTCP)? If so, what should this role be, and what mechanisms should be put ir place for this purpose? 

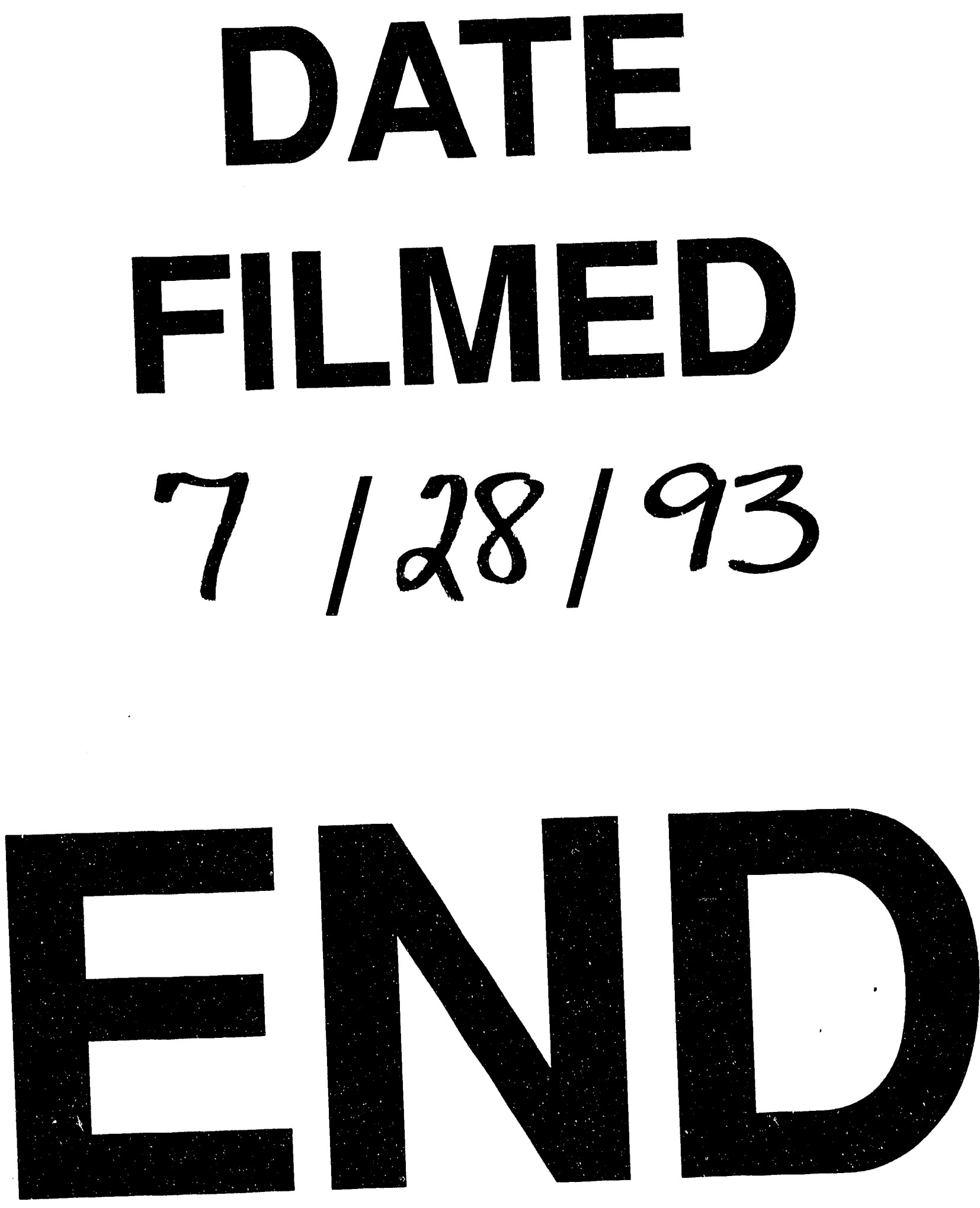
